\title{
Competing ion behavior in direct electrochemical selenite reduction
}

\author{
Shiqiang Zou and Meagan S. Mauter* \\ Department of Civil and Environmental Engineering, Stanford University, Stanford, \\ California 94305, USA
}

${ }^{*}$ Corresponding author.

Meagan S. Mauter. Phone: (650) 725-4911; e-mail: mauter@stanford.edu

Supporting Information contains: 1) Details on electrode regeneration and Se deplating; 2) performance of regenerated electrodes; 3) detailed method for quantifying performance metrics; 4) results for cathodic competing ion behavior of sulfate, nitrate, and nitrite in two-component systems; and 5) electrochemical Se(IV) removal in simulated FGD wastewater through a six-electrode reduction pathway.

Total pages: 5 excluding cover page

Total Figures: 3

Total Equations: 5 


\section{Electrode regeneration and Se deplating}

In the SeDER process, the generated $\operatorname{Se}(0)$ will be either adhere to the electrode surface in the six-electron $\mathrm{Se}(\mathrm{IV})$ reduction or firmly plate on the Au surface in a four-electron $\mathrm{Se}(\mathrm{IV})$ reduction. Buildup of these $\mathrm{Se}(0)$ deposits can result in electric potential loss, deteriorated mass transport, and diminished Se removal rate over the time. Hence, we further explore effective methods to remove surface Se deposits.

Physical methods, such as sonication, are effective in removing the outer layers of the insulative $\mathrm{Se}(0)$ deposits generated in six-electron $\mathrm{Se}(\mathrm{IV})$ reduction but do not remove closely-attached $\mathrm{Se}(0)$ deposits. Instead, we use electrochemical oxidation to regenerate the $\mathrm{Au}$ surface and remove a majority of surface deposits. This periodic electrode maintenance is recommended in our prototype batch reactor for $\mathrm{Se}(\mathrm{VI})$ removal. Past work suggests that $\operatorname{Se}(0)$ buildup may be mitigated by increasing hydraulic sheer force, for instance, by using a rotating cylinder electrode in scaled-up SeDER systems. ${ }^{32}$

Conductive $\mathrm{Se}(0)$ deposits generated in a four-electron $\mathrm{Se}(\mathrm{IV})$ reduction are firmly plated on the electrode, and they can be completely removed by exerting an oxidative potential on $\mathrm{Au}(1.1 \mathrm{~V}$ vs. $\mathrm{Ag} / \mathrm{AgCl})$. Oxidation of $\mathrm{Se}(0)$ happens immediately with a peak current over $10 \mathrm{~mA}$ (Fig. S1), releasing soluble Se ions into solution. Note that this high concentration, high purity solution may find commercial value in applications as diverse as fertilizers, pigments, and photovoltaics. ${ }^{33}$ The area of metallic $\operatorname{Se}(0)$ on Au surface gradually disappears over the 10-min oxidation (Video 1), while the current gradually drops to $<100 \mu \mathrm{A}$. We expect that the need for electrode regeneration will be less frequent in the four-electron reduction pathway, due to a continuous plating of conductive crystalline $\operatorname{Se}(0)$ at $80^{\circ} \mathrm{C}$. As described in the main manuscript, however, electrode regeneration will be required when the resistance of the $\operatorname{Se}(0)$ layer begins to limit electron conductivity to the interface (i.e., over a threshold $\operatorname{Se}(0)$ deposition capacity of $3.5 \mathrm{~g} \mathrm{~cm}^{-2}$ ). Besides electrochemical oxidation, continuous physical scraping may be utilized to remove the conductive $\operatorname{Se}(0)$ layer in scaled-up systems. 


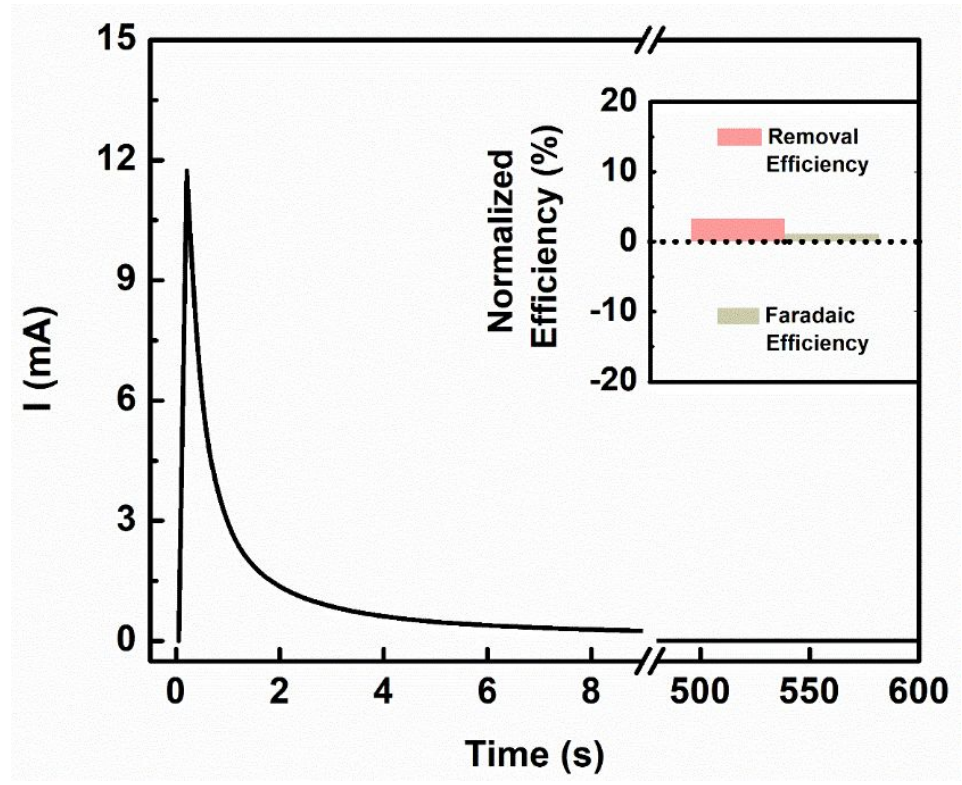

Figure S1. A typical current profile during Au electrode regeneration (or deplating) to remove conductive $\mathrm{Se}(0)$ deposits generated in a four-electron $\mathrm{Se}(\mathrm{IV})$ reduction. The inset figure demonstrates changes in normalized removal and Faradaic efficiencies between two successive batch tests (with electrode regeneration in between).

\section{Performance of regenerated electrode}

We further evaluate the performance of four-electron $\mathrm{Se}(\mathrm{IV})$ reduction using a regenerated Au electrode. A slight increase in both Se removal and Faradaic efficiencies are observed (3.4\% and $1.2 \%$, respectively), compared to the previous test using a pristine Au (Fig. S1, inset). This minor performance enhancement may result from a residual $\mathrm{Au}-\mathrm{Se}$ composite layer after the regeneration, facilitating Se deposition in the subsequent four-electron $\mathrm{Se}(\mathrm{IV})$ reduction. Another possible explanation could be $\mathrm{Pt}$ deposition on cathode from anodic dissolution of $\mathrm{Pt}$ counter electrode $\left(\mathrm{E}^{\mathrm{o}}\left(\mathrm{Pt}^{2+} / \mathrm{Pt}\right)=0.99 \mathrm{~V}\right.$, vs. $\left.\mathrm{Ag} / \mathrm{AgCl}\right),{ }^{34,35}$ acting as a catalyst to promote $\mathrm{Se}(0)$ deposition at $80^{\circ} \mathrm{C}$. This Pt dissolution may take place towards the end of each batch test, owing to an increasing anodic overpotential over the course of a 24-h deposition cycle ( $\mathrm{E}_{\text {anode }}$ $=1.1 \mathrm{~V}$ to $1.4 \mathrm{~V}$, vs. $\mathrm{Ag} / \mathrm{AgCl})$. Our results suggest the need for comprehensive characterization of cathode surface using SEM-EDS and Raman Spectroscopy, especially after long-term $\operatorname{Se}(0)$ plating operations. In either case, a "pre-conditioned" electrode offers enhanced Se removal performance, extending the lifespan of the $\mathrm{Au}$ 
electrode with reduced maintenance and material costs. The reversibility of electrochemical $\mathrm{Se}(0)$ plating and deplating also promotes Se recovery from industrial and agricultural wastewaters.

\section{Quantification of performance metrics}

The Se removal efficiency $(E, \%)$ was quantified as

$$
E=\frac{C_{i} \times V_{i}-C_{f} \times V_{f}}{C_{i} \times V_{i}} \times 100 \%
$$

where $C_{i}$ and $C_{f}\left(\mathrm{mg} \mathrm{L}^{-1}\right)$ are the initial and final Se concentration in the water matrix, and $V_{i}$ and $V_{f}(\mathrm{~L})$ are the initial and final solution volume. Similarly, the Se removal rate $\left(R, \mathrm{mg} \mathrm{m}^{-2} \mathrm{~h}^{-1}\right)$ was estimated as

$$
R=\frac{C_{i} \times V_{i}-C_{f} \times V_{f}}{A \times t} \times \frac{3600 s}{h}
$$

where $t(\mathrm{~s})$ is the operation time. The theoretical Se deposition capacity $\left(D_{\text {theorectical }}, \mathrm{mg}\right.$ $\mathrm{m}^{-2}$ ) or the observed Se deposition capacity $\left(D_{\text {observed }}, \mathrm{mg} \mathrm{m}^{-2}\right)$ was determined by

$$
\begin{array}{r}
\mathrm{D}_{\text {theorectical }}=\frac{\Sigma(\mathrm{I} \times \mathrm{t})}{\mathrm{n} \times \mathrm{F} \times \mathrm{A}} \\
\mathrm{D}_{\text {observed }}=\frac{\mathrm{C}_{\mathrm{i}} \times \mathrm{V}_{\mathrm{i}}-\mathrm{C}_{\mathrm{f}} \times \mathrm{V}_{\mathrm{f}}}{\mathrm{A}}
\end{array}
$$

where $I(\mathrm{~A})$ and $t(\mathrm{~s})$ are the current and time profiles recorded by potentiostat, $n(4$ or 6) is determined by Se reduction pathway, $F$ is Faraday constant $\left(96485 \mathrm{C} \mathrm{mol}^{-1}\right)$, and $A$ is the effective electrode area $\left(\mathrm{m}^{-2}\right)$. We also quantified the Faradaic efficiency $(F, \%)$ of SeDER by

$$
\mathrm{F}=\frac{\mathrm{D}_{\text {observed }}}{\mathrm{D}_{\text {theoretical }}} \times 100 \%
$$

\section{Cathodic competing ion behavior in two-component systems}



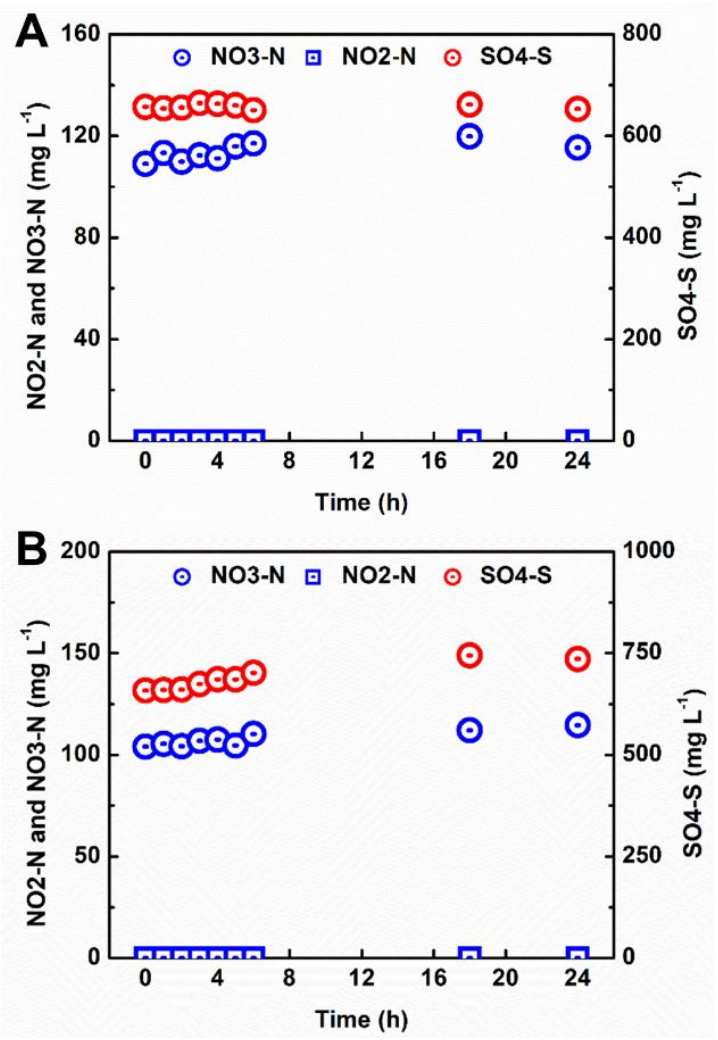

Figure S2. Cathodic competing ion behavior in two-component systems regarding the concentration profile of sulfate, nitrate, and nitrite in (A) a six-electron Se(IV) reduction pathway at $20^{\circ} \mathrm{C}$ and (B) a four-electron $\mathrm{Se}(\mathrm{IV})$ reduction pathway at $80{ }^{\circ} \mathrm{C}$. 


\section{Electrochemical Se(IV) removal in simulated FGD wastewater through a six-}

electrode reduction pathway
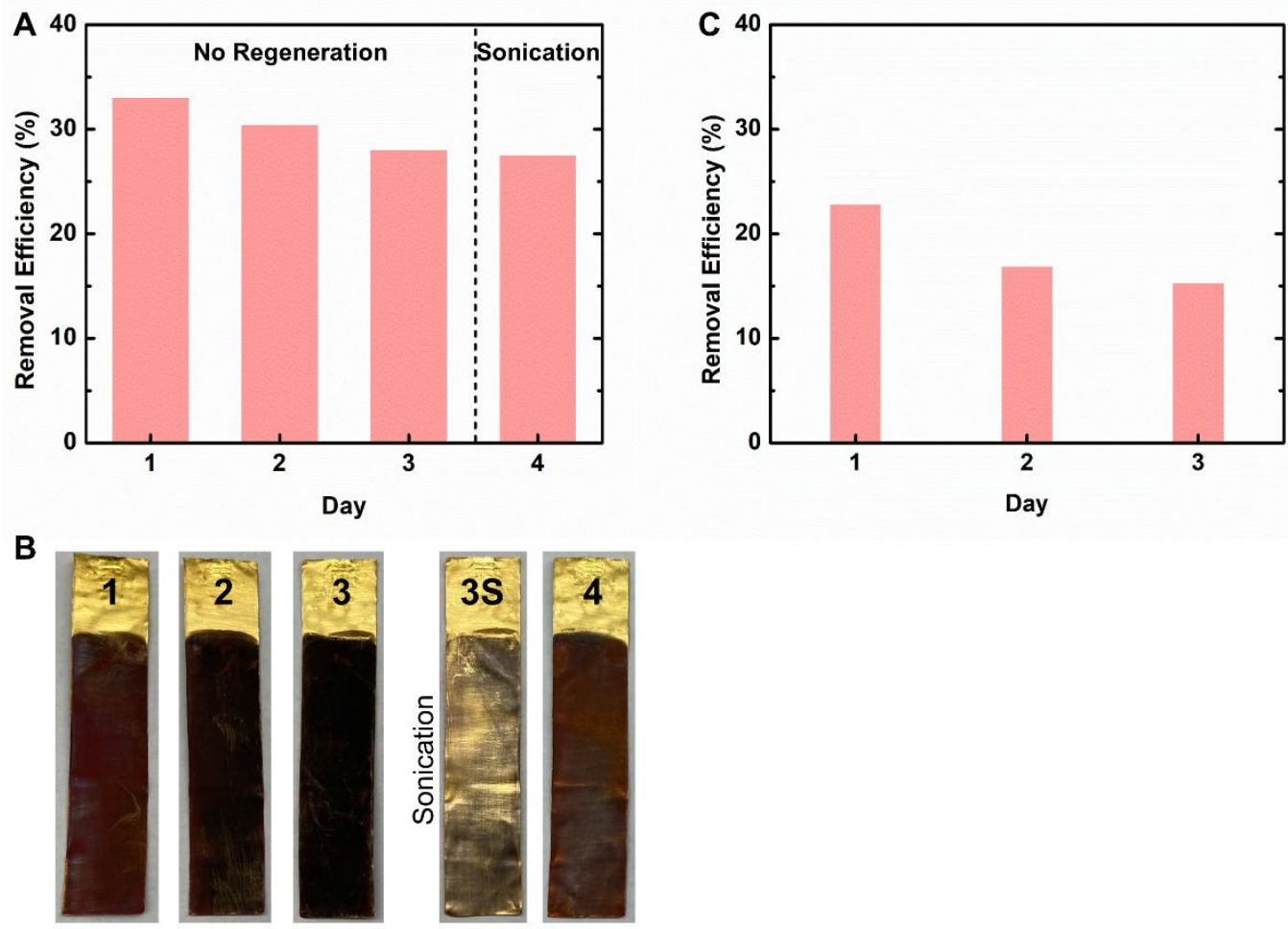

Figure S3. Electrochemical Se(IV) removal in simulated FGD wastewater through a six-electrode reduction pathway regarding (A) Se removal efficiency at $20^{\circ} \mathrm{C}$, (B) surface-attached insulative $\mathrm{Se}(0)$ over the 4-day operation, and (C) Se removal efficiency at $80{ }^{\circ} \mathrm{C}$. In Fig. S3B, the numbers on each $\mathrm{Au}$ electrode stand for the electrode at the end of each day, with " $3 \mathrm{~S}$ " standing for the Au electrode on the $3^{\text {rd }}$ day after sonication to remove the loosely attached $\operatorname{Se}(0)$. 